Movere Journal Vol. 4 No. 1 Januari 2022 Hal. 1 - 10

MOVERE JOURNAL

http://ojs.stie-tdn.ac.id/index.php/mv

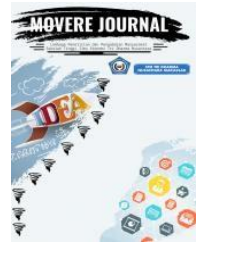

\title{
PENGARUH KOMITMEN ORGANISASI, BUDAYA ORGANISASI DAN KOMPENSASI TERHADAP KEPUASAN KERJA SEBAGAI VARIABEL INTERVENING TERHADAP KINERJA PADA KANTOR DINAS KOPERASI DAN UKM KOTA MAKASSAR
}

\author{
Lukman', Akhmad Muhammadin² \\ Program Pascasarjana Sekolah Tinggi Ilmu Ekonomi Makassar Bongaya \\ Email: lukman.pertanian@gmail.com¹‥muhammadin.akhmad@yahoo.com²
}

\begin{abstract}
Abstrak : Jenis penelitian yang digunakan adalah esplanatory survey (penjelasan) yang bersifat deskriptif analisis dengan pendekatan menggunakan pendekatan kuatitatif dan diproses datanya sehingga berwujud pada data bilangan (angka), populasi pada penelitian ini yaitu seluruh pegawai Dinas koperasi dan UKM kota Makassar berjumlah 48 responden. Teknik pengambilan sampel yaitu dengan menggunakan sampling jenuh (total sample). Analisis data yang digunakan dalam menguji hipotesis yaitu analisis Partial Least Square (PLS). Hasil pengujian parsial pada path coefficients menunjukkan bahwa komitmen organisasi dan kepuasan kerja berpengaruh positif dan signifikan terhadap kinerja, sedangkan budaya organisasi dan kompensasi tidak berpengaruh signifikan terhadap kinerja. Komitmen organisasi berpengaruh positif dan tidak signifikan terhadap kepuasan, budaya organisasi dan kompensasi berpengaruh positif dan signifikan terhadap kepuasan kerja.
\end{abstract}

Kata Kunci : Budaya organisasi, Komitmen organisasi, Kompensasi, Kepuasan dan Kinerja.

\begin{abstract}
The type of research used is descriptive esplanatory survey (explanation) analysis using a quantitative approach and processing the data so that it is tangible in number data, the population in this study namely all employees of the Makassar City Cooperatives and SMEs Service amounted 48 respondents. The sampling technique is by using saturated sampling (total sample). Analysis of the data used in testing the hypothesis, namely Partial Least Square (PLS). The partial test results on path coefficients show that organizational commitment and job satisfaction have a positive and significant effect on performance, while organizational culture and compensation have no significant effect on performance. Organizational commitment has a positive and insignificant effect on satisfaction, organizational culture and compensation have a positive and significant effect on job satisfaction.
\end{abstract}

Keyword : Organizational culture, organizational commitment, compensation, satisfaction and performance. 


\section{A. PENDAHULUAN}

Peningkatan kinerja pegawai tentunya akan membawa kemajuan bagi instansi di masa yang akan datang serta akan mampu untuk bertahan dalam kondisi yang tidak di inginkan seperti pada masa pandemi Covid19 saat ini. Hal ini disebabkan karena Sumber Daya Manusia (SDM) adalah faktor sentral dalam suatu organisasi. Apapun bentuk serta tujuannya, organisasi dibuat berdasarkan berbagai visi untuk kepentingan manusia dan dalam pelaksanaan misinya dikelola dan dijalankan oleh manusia. Jadi, manusia merupakan faktor strategis dalam semua kegiatan organisasi.

Menurut pandangan ahli menjelaskan bahwa kinerja karyawan secara umum dipengaruhi oleh dua faktor, yaitu faktor internal dan eksternal (Ismail, 2006 dalam Taurisa, 2012). Faktor internal merupakan faktor yang berasal dari dalam diri karyawan, salah satu faktor tersebut yaitu tingkat kepuasan kerja karyawan dalam bekerja serta komitmen karyawan dalam organisasi. Sedangkan faktor eksternal merupakan faktor yang berasal dari luar diri karyawan, seperti budaya organisasi dan pemberian kompensasi.

Berdasarkan pada teori yang dikemukan oleh Mathis dan Jackson (2001) Teori tersebut menjelaskan bahwa Kemampuan (ability) adalah kemampuan alami yang melibatkan bakat dan minat yang tepat untuk pekerjaan yang diberikan, pada penelitian ini di interpretasikan melalui tingkat kepuasan pegawai dalam bekerja yang tentunya akan menciptakan bakat serta minat dalam mengerjakan suatu pekerjaan. Usaha (efford) adalah suatu praktik yang diperlukan untuk kegiatan organisasi yang aman dan efisien, hal ini dapat dicerminkan melalui penciptaan komitmen yang tinggi pada diri karyawan, kemudian dukungan organisasi (support) adalah dukungan yang diterima dari organisasinya, dalam hal ini dicerminkan dari kemampuan perusahaan menciptakan budaya organisasi yang baik bagi karyawan dan pemberian kompensasi yang adil.

\section{B. TELAAH LITERATUR DAN PENGEMBANGAN HIPOTESIS}

\section{Manajemen Sumber Daya Manusia}

Manajemen Sumber Daya Manusia adalah suatu bidang manajemen yang khusus mempelajari hubungan dan peranan manusia dalam organisasi perusahaan.Manajemen SDM merupakan hal-hal yang mencakup tentang pembinaan, penggunaan dan perlindungan sumber daya manusia baik yang berada dalam hubungan kerja maupun yang berusaha sendiri. Menurut Hasibuan (2010), mendefinisikan MSDM sebagai ilmu dan seni mengatur hubungan dan peranan tenaga kerja agar efektif dan efisien membantu terwujudnya tujuan perusahaan, karyawan dan masyarakat. Sedangkan pendapat lain mengemukakan bahwa manajemen sumber daya manusia adalah suatu proses yang terdiri atas perencanaan, pengorganisasian, pemimpinan dan pengendalian kegiatankegiatan yang berkaitan dengan analisis pekerjaan, evaluasi pekerjaan, pengadaan, pengembangan, kompensasi, promosi, dan pemuusan hubungan kerja guna mencapai tujuan yang telah ditetapkan (Panggabean, 2004).

\section{Kepuasan Kerja.}

Menurut Priansa (2011) mengemukakan, bahwa kepuasan kerja adalah kesukaan atau ketidaksukaan pegawai terhadap pekerjaannya. Kepuasan kerja suatu sikap umum seorang pekerja kepada pekerjaannya. Pandangan lainnya menjelaskan bahwa kepuasan kerja adalah sikap para pekerja terhadap pelayanan yang 
diberikan, sikap itu berasal dari persepsi mereka tentang pekerjaannya.

Tinggi rendahnya kepuasan kerja dapat diukur dengan menggunakan 5 (lima) indikator (Novi Susanti dan Haryani 2020) yaitu:

a. Sistem Pekerjaan. Pegawai cenderung menyukai pekerjaan yang memberi kesempatan supaya menggunakan kemampuan dan keterampilannya, kebebasan, atau umpan balik tentang betapa baik mereka bekerja. Karakteristik tersebut membuat kerja agar menantang. Pekerjaan yang kurang menantang memberikan efek kebosanan, akan tetapi banyak menantang juga dapat menciptakan frustasiserta perasaan gagal.

b. Pembayaran Upah. Pegawai menginginkan sistem upah/gaji hingga kebijakan promosi yang adil, tidak meragukan hingga segaris dengan apa menjadi pengharapannya. Apabila gaji dilihat dengan adil yang didasarkan pada suatutuntutan pekerjaan, tingkat keterampilan individu, serta standar pengupahan komunitas kemungkinan besar bisa menghasilkan kepuasan

c. Promosi. Promosi terjadi ketika pegawai berpindah dari pekerjaan ke posisi yang lebih tinggi, dengan tanggungjawab hingga jenjang organisasionalnya. Pada waktu dipromosikan pegawai biasanya menghadapi peningkatan tuntutan serta keahlian, kemampuan dan tanggung jawab. Pegawai merasa positif karena adanya promosi jabatan yang dilakukan. Promosi disini maksudnya ialah bagaimana organisasi dalam mendayagunakan kemampuan serta keahlian pegawai setinggi mungkin.

d. Pengawasan. Seseorang yang selalu memberikan perintah atau petunjuk untuk melaksanakan kerja. Contohnya: karyawan akan cenderung merasa puas apabila mendapatkan perilaku adil dan dukungan dari atasan serta mengawasi kinerja pegawai secara berkala demi hasil produktivitas yang maksimal.

e. Rekan Kerja. Sesama teman saling membantu atau senantiasa berinteraksi dalam melaksanakan setiap pekerjaan. Setiap orang akan mampu merasakan rekan kerjannya sangat menyenangkan atau tidak menyenangkan.

\section{Komitmen Organisasi}

Komitmen organisasional sebagai sebuah keadaan yang mengkarakteristikan hubungan karyawan dengan organisasi atau implikasinya yang mempengaruhi apakah karyawan akan tetap bertahan dalam organisasi atau tidak, yang teridentifikasi dalam tiga komponen yaitu komitmen afektif, komitmen kontinyu, dan komitmen normatif. Salah satu pandang ahli yaitu Luthans (2006) dalam Fitryianur (2013) mengatakan bahwa komitmen organisasional adalah keinginan kuat untuk tetap sebagai anggota organisasi, keinginan untuk berusaha kerasa sesuai keinginan organisasi, keyakinan tertentu, dan penerimaan nilai dan tujuan organisasi.

Ada tiga komponen dalam bentuk komitmen organisasional Fitryianur (2013), yaitu: Komitmen afektif (affective commitment) Merupakan keinginan karyawan untuk menjadi bagian dari organisasi karena adanya ikatan emosional.

a. Komitmen kontinyu (Continuance commitmen) merupakan keinginan karyawan untuk tetap bertahan pada suatu organisasi karena membutuhkan gaji dan keuntungankeuntungan lain, atau karena karyawan tersebut tidak menemukan pekerjaan lain.

b. Komitmen normatif (Normative Commitment) merupakan perasaan mengharuskan untuk tbertahan dalam organisasi dikarenakan kewajiban dan tanggungjawab terhadap organisasi yang didasari atas pertimbangan norma, nilai, dan keyakinan karyawan. 


\section{Budaya Organisasi}

Budaya organisasi merupakan suatu kekuatan sosial yang tidak tampak. Yang dapat menggerakkan orang-orang dalam suatu organisasi untuk melakukan aktivitas kerja (Sutrisno, 2019). Secara tidak sadar, tiap-tiap orang di dalam suatu organisasi mempelajari budaya yang berlaku di dalam organisasinya. Apalagi bila ia sebagai orang baru supaya dapat diterima oleh lingkungan tempat bekerja, ia berusaha mempelajari apa yang dilarang dan apa yang diwajibkan, apa yang baik dan apa yang buruk, apa yang benar dan apa yang salahdan apa yang harus dilakukan dan apa yang tidak boleh dilakukan di dalam organisasi tempat mereka bekerja. Pengukuran baik buruknya budaya oragnisasi dapat diukur dengan menggunakan indikator (McShane, et al, 2005) dalam Octaviana, (2011) yaitu:

a. Budaya Pengendalian. Budaya ini menilai peran eksekutif senior untuk memimpin organisasi. Tujuannya adalah untuk mempertahankan semua orang berjalan searah dan dibawah kendali.

b. Budaya Profesionalisme. Budaya ini menilai kompetensi untuk melaksanakan tugas dan fungsinya secara baik dan benar dan juga komitmen dari para anggota dari sebuah profesi untuk meningkatkan kemampuan dari seorang karyawan.

c. Budaya Hubungan. Budaya ini menilai sifat pengasuhan dan kemanusiaan. Ini mempertimbangkan komunikasi terbuka, keadilan, kerja tim, dan pembagian bagian-bagian penting dalam kehidupan organisasi.

d. Budaya Responsif. Budaya ini menilai kemampuannya untuk menyesuaikan diri dengan lingkungan eksternal, termasuk kompetitif dan merealisasikan kesempatan baru.

\section{Kompensasi}

Kompensasi adalah keseluruhan balas jasa yang diterima pegawai sebagai akibat dari pelaksanaan pekerjaan di organisasi dalam bentuk uang atau lainnya yang dapat berupa gaji, upah, bonus, insentif, dan tunjangan lainnya seperti tunjangan kesehatan, tunjangan hari raya, uang makan, uang cuti dan lain-lain (Yuli, 2013). Tinggi rendahnya kompensasi yang diberikan perusahaan dapat diukur dengan indikator (Simamora, 2004; dalam Jufrizen, 2017).

a. Upah dan Gaji Upah dan gaji merupakan hal yang berbeda. Upah merupakan basis bayaran yang kerap kali digunakan bagi pekerja-pekerja produksi dan pemeliharaan atau untuk pekerja harian yang bukan pegawai atau karyawan tetap. Pemberian upah biasanya bersifat harian, mingguan atau bulanan sesuai dengan kesepakatan antara pekerja dengan pemberi kerja. Gaji umumnya berlaku untuk tarif bayaran mingguan, bulanan, atau tahunan yang diberikan secara tetap.

b. Insentif. Insentif merupakan tambahan kompensasi di atas atau di luar gaji atau upah yang diberikan oleh organisasi. Insentif biasanya diberikan oleh perusahaan atas dasar prestasi kerja karyawan atau produktivitas karyawan. Karyawan dengan prestasi atau produktivitas kerja yang baik maka akan mendapat insentif dari perusahaan.

c. Tunjangan. Tunjangan merupakan pembayaran atau jasa yang diberikan oleh instansi sebagai pelindung atau pelengkap gaji pokok yang diterima pegawai. Contoh-contoh tunjangan adalah asuransi kesehatan dan jiwa, liburan yang ditanggung instansi, program pension, dan tunjangan 
lainnya yang berkaitan dengan hubungan kepegawaian.

d. Fasilitas. Pemberian kompensasi yang berbentuk fasilitas diberikan oleh perusahaan untuk memperlancar dan mempermudah serta memotivasi karyawan atau pegawai dalam bekerja. Contoh fasilitas adalah kenikmatan/fasilitas seperti mobil perusahaan, keanggotaan klub, tempat parkir khusus, atau akses internet, seragam kerja, dan sebagainya

\section{Kinerja Karyawan}

Teori yang dikemukan oleh Mathis dan Jackson (2001) dalam teori tersebut menjelaskan bahwa Kemampuan (ability) adalah kemampuan alami yang melibatkan bakat dan minat yang tepat untuk pekerjaan yang diberikan. Usaha (efford) adalah suatu praktik yang diperlukan untuk kegiatan organisasi yang aman dan efisien. Dukungan organisasi (support) adalah dukungan yang diterima dari organisasinya. Tinggi rendahnya kinerja dalam penelitian ini mengadopsi pengukuran Mangkunegara (2009) dalam Yusantiana (2015).

a. Kualitas. Kualitas. Merupakan seberapa baik seorang karyawan mengerjakan apa yang seharusnya dikerjakan.

b. Kuantitas. Merupakan seberapa lama seorang pegawai bekerja dalam satu harinya. Kuantitas kerja ini dapat dilihat dari kecepatan kerja setiap pegawai itu masing-masing.

c. Pelaksanaan tugas. Merupakan seberapa jauh karyawan mampu melakukan pekerjaanya dengan akurat dan tidak ada kesalahan.

d. Tanggung Jawab. Merupakan kesadaran akan kewajiban karyawan untuk melaksanakan pekerjaan yang diberikan perusahaan.

Gambar 1. Kerangka Konseptual

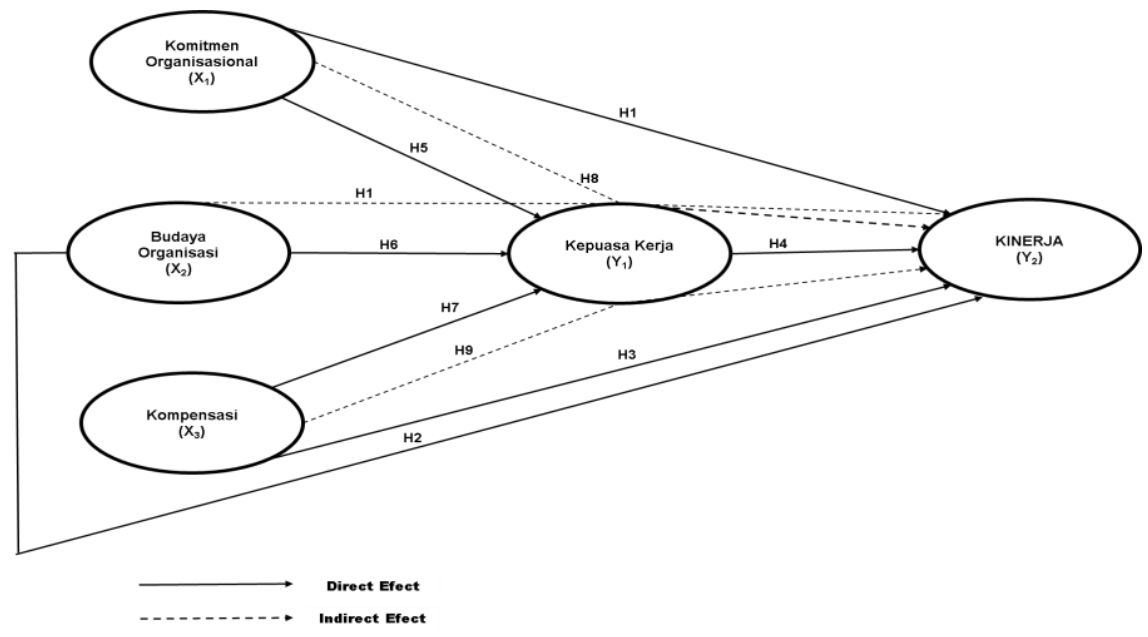

\section{METODE PENELITIAN}

Pendekatan yang dilakukan dalam penelitian ini adalah pendekatan kuantitatif melalui explanatory survey, penelitian kuantitatif adalah penelitian yang dalam penelitianya banyak dituntut menggunakan angka, mulai dari pengumpulan data, penafsiran terhadap data tersebut, serta penampilan dan hasilnya dalam penelitian. Menurut Sugiyono, (2013) explanatory survey merupakan penelitian yang 
mengambil sampel dari suatu populasi yang diteliti dan menjelaskan hubungan klasual antara variable-variabel yang akan melalui pengujian hipotesis.

Analisis data dalam penelitian ini dilakukan dengan menggunakan model persamaan structural Partial Least Square (PLS).Partial Least Square (PLS) merupakan metode analisis yang powerful karena tidak mengasumsikan data harus dengan pengukuran tertentu, dapat diterapkan pada semua skala data, tidak membutuhkan banyak asumsi dan ukuran sample (Ghozali, 2006). Selain itu alasan peneliti menggunakan structural Partial Least Square (PLS) disebabkan model penelitian yang dibangun dalam penelitian ini yaitu model yang kompleks yaitu bukan hanya menjelaskan pengaruh secara langsung akan tetapi menjelaskan pengaruh tidak langsung (Intervening) suatu variabel.

Penelitian ini menggunakan teknik SEM-PLS, sehingga evaluasi yang dilakukan terhadap dua model yaitu outer model dan inner model. Outer model menentukan spesifikasi hubungan antara konstruk laten dengan indikatornya.

Keterangan: $\quad \mathrm{x}=\Pi \mathrm{x} \xi+\varepsilon \mathrm{x}$

$\mathrm{y}=\Pi y \eta+\varepsilon y$

$\mathrm{X}$ : matriks variabel manifest yang berhubungan dengan konstruk laten eksogen $\xi$

Y : matriks variabel manifest yang berhubungan dengan konstruk laten endogen $\eta$
Пx dan Пy : matriks koefisien (matriks loading)

Ex dan Ey : matriks outer model residu Persamaan dari inner model adalah sebagai berikut:

Keterangan: $\quad \eta=\eta \beta+\xi \Gamma+\zeta$

$\eta$ : matriks konstrak laten endogen

$\xi$ : matriks konstrak laten eksogen

$\beta$ : koefisien matriks variabel endogen

$\Gamma$ : koefisien matriks variabel eksogen

$\zeta$ : inner model residual matriks

Pengujian model hubungan struktural secara matematik dirumuskan:

a. $\quad \mathrm{Y} 1=\rho 1 \mathrm{Y} 1 \mathrm{X} 1+\rho 2 \mathrm{Y} 1 \mathrm{X} 2+$ $\rho 3 Y 1 X 3 \ldots . . . . . . . . . . . e 1$

b. $Y 2=\rho 1 Y 2 X 1+\rho 2 Y 2 X 2+\rho 3 Y 2 X 3+$ $\rho 2 \mathrm{Y} 2 \mathrm{Y} 1+\ldots . . . . . . . \mathrm{e} 2$

dimana : $X_{1}=$ Komitmen organisasi

$\mathrm{X}_{2}=$ Budaya Organisasi

$\mathrm{X}_{3}=$ Kompensasi

$\mathrm{Y}_{1}=$ Kepuasan Kerja

$\mathrm{Y}_{2}=$ Kinerja

$\mathrm{e}=$ Standar Error

\section{HASIL DAN PEMBAHASAN}

Convergent validity dari model pengukuran dapat dilihat dari korelasi antara skor indikator dengan skor konstruknya (loading factor). suatu model dikatakan baik dan memenuhi pengujian Convergent Validity apabila nilai loading faktor dari setiap indikator $\geq 0.60$ dianggap signifikan. Hasil pengolahan Convergent validity dalam pengujian WarpPLS Versi 7.0 dapat dijelaskan pada tabel berikut:

Tabel 1. Convergent validity

\begin{tabular}{|c|c|c|c|c|c|c|}
\hline \multicolumn{7}{|c|}{ Combined loadings and cross-loadings } \\
\hline Model & KO & B.Orgn & Komp & Kps.K & KP & P value \\
\hline X11 & 0.842 & & & & & $<0.001$ \\
\hline X12 & 0.753 & & & & & $<0.001$ \\
\hline X13 & 0.876 & & & & & $<0.001$ \\
\hline X21 & & 0.698 & & & & $<0.001$ \\
\hline X22 & & 0.878 & & & & $<0.001$ \\
\hline
\end{tabular}




\begin{tabular}{|c|c|c|c|c|c|}
\hline X23 & 0.839 & & & & $<0.001$ \\
\hline X24 & 0.863 & & & & $<0.001$ \\
\hline X31 & & 0.957 & & & $<0.001$ \\
\hline $\mathrm{X32}$ & & 0.919 & & & $<0.001$ \\
\hline X33 & & 0.934 & & & $<0.001$ \\
\hline X34 & & 0.672 & & & $<0.001$ \\
\hline Y11 & & & 0.803 & & $<0.001$ \\
\hline Y12 & & & 0.780 & & $<0.001$ \\
\hline Y13 & & & 0.826 & & $<0.001$ \\
\hline Y14 & & & 0.618 & & $<0.001$ \\
\hline Y15 & & & 0.719 & & $<0.001$ \\
\hline Y21 & & & & 0.864 & $<0.001$ \\
\hline Y22 & & & & 0.834 & $<0.001$ \\
\hline Y23 & & & & 0.856 & $<0.001$ \\
\hline Y24 & & & & 0.776 & $<0.001$ \\
\hline
\end{tabular}

Sumber : Data diolah SPSS (2021)

Syarat untuk memenuhi syarat validitas diskriminan ini adalah hasil dalam view combined loading and cross-loadings menunjukkan bahwa loading ke konstruk lain (cross-loading) bernilai lebih rendah daripada loading ke konstruk variabel.

Tabel 2. Deskriminant validity

\begin{tabular}{|l|c|c|c|c|c|c|c|c|}
\hline \multirow{2}{*}{ Model } & \multirow{2}{*}{ Loading } & \multicolumn{7}{|c|}{ Combined loadings and cross-loadings } \\
\cline { 3 - 8 } & & & KO & B.Orgn & Komp & Kps.K & KP & P value \\
\hline X11 & 0.842 & $>$ & & 0.238 & -0.332 & -0.252 & 0.117 & $<0.001$ \\
\hline X12 & 0.753 & $>$ & & -0.257 & 0.741 & 0.380 & -0.418 & $<0.001$ \\
\hline X13 & 0.876 & $>$ & & -0.007 & -0.318 & -0.085 & 0.248 & $<0.001$ \\
\hline X21 & 0.698 & $>$ & -0.470 & & 0.377 & -0.827 & 0.850 & $<0.001$ \\
\hline X22 & 0.878 & $>$ & -0.228 & & 0.053 & 0.077 & -0.047 & $<0.001$ \\
\hline X23 & 0.839 & $>$ & 0.337 & & -0.170 & 0.491 & -0.555 & $<0.001$ \\
\hline X24 & 0.863 & $>$ & 0.284 & & -0.195 & 0.113 & -0.100 & $<0.001$ \\
\hline X31 & 0.957 & $>$ & -0.276 & 0.166 & & -0.188 & 0.176 & $<0.001$ \\
\hline X32 & 0.919 & $>$ & -0.281 & 0.188 & & -0.260 & 0.093 & $<0.001$ \\
\hline X33 & 0.934 & $>$ & 0.119 & -0.252 & & 0.349 & -0.294 & $<0.001$ \\
\hline X34 & 0.672 & $>$ & 0.612 & -0.143 & & 0.140 & 0.030 & $<0.001$ \\
\hline Y11 & 0.803 & $>$ & 0.353 & -0.19 & -0.145 & & -0.493 & $<0.001$ \\
\hline Y12 & 0.780 & $>$ & -0.401 & -0.027 & 0.361 & & -0.140 & $<0.001$ \\
\hline Y13 & 0.826 & $>$ & -0.283 & 0.055 & 0.031 & & 0.280 & $<0.001$ \\
\hline Y14 & 0.618 & $>$ & -0.414 & 0.262 & 0.462 & & 0.638 & $<0.001$ \\
\hline Y15 & 0.719 & $>$ & 0.723 & -0.048 & -0.663 & & -0.169 & $<0.001$ \\
\hline Y21 & 0.864 & $>$ & 0.014 & 0.107 & -0.174 & -0.085 & & $<0.001$ \\
\hline Y22 & 0.834 & $>$ & -0.333 & 0.221 & -0.066 & -0.207 & & $<0.001$ \\
\hline Y23 & 0.856 & $>$ & 0.185 & -0.11 & 0.179 & -0.104 & & $<0.001$ \\
\hline
\end{tabular}




\section{Y24}

0.776

0.139

$-0.235$

0.067

0.432

$<0.001$

Sumber : Data diolah SPSS (2021)

Dari tabel diatas menjelaskan bahwa seluruh indikator pada variabel dalam penelitian ini telah memenuhi standar Discriminant validity yang dibuktikan dengan nilai loading ke konstruk lain lebih rendah dibanding nilai loading ke konstruknya sendiri pada kolom yang sama. Sehingga dapat dilanjutkan pada composite reliability.

Tabel 3. Goodness of fit

\begin{tabular}{|c|c|c|c|}
\hline Goodness of fit & indeks & $\begin{array}{c}\boldsymbol{P} \text { - } \\
\text { Value }\end{array}$ & Kriteria \\
\hline Average path coefficient (APC) & 0.340 & 0.002 & $<0.05$ \\
\hline Average R-squared (ARS) & 0.629 & $<0.001$ & $<0.05$ \\
\hline Average adjusted R-squared (AARS) & 0.600 & $<0.001$ & $<0.05$ \\
\hline $\begin{array}{c}\text { Average full collinearity VIF } \\
\text { (AFVIF) }\end{array}$ & 2.205 & & $\mathrm{AFVIF}<5$ \\
\hline
\end{tabular}

Sumber : Data diolah SPSS (2021)

Pada tabel diatas menjelaskan bahwa nilai Average path coefficient (APC) sebesar 0.340 , p-value 0.002 , Average $R$-squared (ARS) sebesar 0.629 dengan nilai $p$-value < 0.001 , sedangkan Average adjusted $R$ squared (AARS) memiliki nilai 0.600 dan p-value < 0.001. Berdasarkan kriteria APC dan ARS serta AARS harus memiliki nilai $p$-value $<0.05$, maka dapat disimpulkan bahwa Inner Model dalam penelitian ini dapat diterima, sehingga model penelitian memenuhi standar pemodelan

\section{E. KESIMPULAN}

Berdasarkan hasil penelitian dan pembahasan pada bab IV, maka dapat dituliskan kesimpulan dari penelitian ini yaitu:

1. Hasil pengujian path coefficients menjelaskan bahwa komitmen organisasi berpengaruh positif dan signifikan terhadap kinerja, hasil tersebut mengindikasikan bahwa komitmen yang tinggi akan memberikan pengaruh yang signifikan dalam meningkatkan kinerja pegawai dalam bekerja.

2. Hasil pengujian path coefficients membuktikan bahwa budaya organisasi memiliki pengaruh negative dan tidak signifikan terhadap kinerja. Hasil tersebut mengindikasikan bahwa budaya organisasi yang rendah tidak akan mampu memberikan pengaruh yang nyata dalam meningkatkan hasil kerja pegawai.

3. Hasil pengujian path coefficients menjelaskan kompensasi memiliki pengaruh positif namun tidak signifikan terhadap kinerja, hasil lainnya menjelaskan bahwa walaupun kompensasi tergolong tinggi namun belum tentu mampu memberikan kontribusi yang nyata dalam meningkatkan kinerja, karena pada dasarnya system kompensasi yang diberikan instansi merupakan sumber motivasi kepada pegawai tetapi belum tentu dapat memengaruhi tinggiRendahnya kinerja pegawai karena adanya

4. Hasil pengujian path coefficients membuktikan bahwa kepuasan kerja 
berpengaruh positif dan signifikan terhadap kinerja, hal ini mengindikasikan bahwa kepuasan kerja yang tinggi akan mampu memberikan pengaruh yang nyata dalam meningkatkan kinerja, semakin tinggi tingkat kepuasan kerja seorang pegawai dalam bekerja maka semakin tinggi kinerjanya yang di hasilkannya.

5. Hasil pengujian path coefficients menjelaskan bahwa komitmen organisasi berpengaruh positif namun tidak signifikan terhadap kepuasan, hal ini mengindikasikan bahwa walaupun komitmen tergolong tinggi namun belum mampu memberikan kontribusi yang nyata dalam meningkatkan kepuasan, karena tingkat kepuasan seseorang terkadang di pengaruhi oleh hubungan baik dengan rekan kerja maupun atasan.

6. Hasil pengujian path coefficients menjelaskan bahwa budaya organisasi memiliki pengaruh positif dan signifikan terhadap kepuasan pegawai, hasil tersebut mengindikasikan bahwa semakin baik budaya organisasi maka semakin tinggi kepuasan kerja, hasil lainnya menjelaskan bahwa budaya organisasi yang baik dalam organisasi akan menciptakan kepuasan pada diri

7. seseorang yang bekerja dalam organisasi tersebut.

8. Hasil pengujian path coefficients menjelaskan bahwa kompensasi memiliki pengaruh positif dan signifikan terhadap kepuasan kerja, hal ini mengindikasikan bahwa semakin tinggi kompensasi yang diterima pegawai maka akan memberikan kontribusi yang nyata dalam meningkatkan kepuasan kerja.

9. Kontribusi pengaruh yang dihasilkan dari seluruh variabel independen yang digunakan dalam penelitian ini sebesar 0.69 atau sebesar $69 \%$ dan sisanyas ebesar $31 \%$ di pengaruhi oleh faktor lain yang tidak di ikutkan pada penelitian ini seperti lingkungan kerja, beban kerja, stress kerja dan lain sebagainya

\section{DAFTAR PUSTAKA}

Ghozali, Imam. (2006). Aplikasi Analisis Multivariate dengan Program SPSS (Edisi Ke 4). Semarang: Badan Penerbit Universitas Diponegoro.

Hasibuan, Malayu. (2003). Manajemen Sumber Daya Manusia. Penerbit: PT. Bumi Aksara, Jakarta.

Jufrizen, J. (2017). Efek Mediasi Kepuasan Kerja Pada Pengaruh Kompensasi Terhadap Kinerja Karyawan. Jurnal Ilmiah Manajemen Dan Bisnis, 17(1).

Luthans, (2006), Perilaku Organisasi. Edisi Sepuluh, PT. Andi: Yogyakarta.

Mangkunegara, A. A. P. (2010). Evaluasi Kinerja SDM (Kedua). Bandung: PT. Refika Aditama.

Mathis. L. Robert dan Jackson. H. John. (2001). Manajemen Sumber Daya Manusia, Jakarta : Buku kedua.

Priansa, D. J., Pd, S. \& Suwatno, D. H. (2011). Manajemen SDM dalam organisasi Publik dan Bisnis. Bandung: Alfabeta.

Shane, S. L., \& Von Glinow, M. A. (2010). Organizational Behavior: Emerging Knowledge and Practice for The Real World (5th ed.). New York: The McGraw-Hill Companies, Inc.

Sugiyono. (2013). Metode Penelitian Kuantitatif, Kualitatif, Dan R\&D. Bandung : Alfabeta.

Susanti, N., \& Haryani, D. S. (2020). Analisis Tingkat Kepuasan Kerja Karyawan Tomo Japanese Restaurant Tanjung pinang. Jurnal Dimensi, 9 (1), 57-73.

Taurisa, C. M., Djastuti, I., \& Ratnawati, I. (2012). Analisis pengaruh budaya organisasi dan kepuasan kerja terhadap komitmen organisasi dalam 
meningkatkan kinerja karyawan (Studi pada PT. Sido Muncul Kaligawe Semarang) (Doctoral dissertation, Diponegoro University).

Yuli, S. (2013). "Pengaruh Kompensasi dan Motivasi Kerja terhadap Kinerja Karyawan pada PT Tunas Hijau Samarinda". eJournal Ilmu Administrasi Bisnis Vol 1 Nomor 1, 41-55 ISSN 0000-0000.
Yusantiana, S. (2015) Pengaruh Kompensasi Terhadap Kinerja Karyawan BPJS Ketenagakerjaan Kantor Cabang Bandung Suci (Doctoral dissertation, Universitas Widyatama).

Sutrisno, (2014), Manajemen Sumber Daya Manusia. Kencana Prenada Media Group, Jakarta.

Panggabean. )2004). "Penilaian Kinerja" (online), (Http: www LPTUI.com) 